2020-07-02

\title{
Measuring quality of life in ALS/MND: validation of the WHOQOL-BREF
}

\section{Young, CA}

http://hdl.handle.net/10026.1/16448

10.1080/21678421.2020.1752244

Amyotrophic Lateral Sclerosis and Frontotemporal Degeneration

Informa UK Limited

All content in PEARL is protected by copyright law. Author manuscripts are made available in accordance with publisher policies. Please cite only the published version using the details provided on the item record or document. In the absence of an open licence (e.g. Creative Commons), permissions for further reuse of content should be sought from the publisher or author. 


\section{Measuring quality of life in ALS/MND: Validation of the WHOQOL-BREF}

Carolyn A. Young

Walton Centre NHS Foundation Trust, Liverpool, UK; University of Liverpool, Liverpool, UK Email:Carolyn.young@thewaltoncentre.nhs.uk

Roger Mills

Walton Centre NHS Foundation Trust, Liverpool, UK

Email: roger.mills@thewaltoncentre.nhs.uk

Ammar Al-Chalabi

King's College London, UK

Email: ammar.al-chalabi@kcl.ac.uk

Georgina Burke

Queen Alexandra Hospital, Portsmouth, UK

Email: Georgina.Burke@porthosp.nhs.uk

Siddharthan Chandran

Royal Infirmary of Edinburgh, Edinburgh, UK

Email: siddharthan.chandran@ed.ac.uk

David J Dick

Norfolk \& Norwich University Hospital, Norfolk, UK

Email:david.dick@nnuh.nhs.uk

John Ealing

Salford Royal Foundation Trust, Manchester, UK

Email: john.ealing@srft.nhs.uk

C. Oliver Hanemann

Plymouth University Peninsula Schools of Medicine and Dentistry, Plymouth, UK

Email: Oliver.Hanemann@plymouth.ac.uk

Timothy Harrower

Royal Devon and Exeter Foundation Trust Hospital, Exeter, UK

Email: timothy.harrower@nhs.net 
Christopher J. McDermott

Sheffield Institute for Translational Neuroscience, Sheffield, UK

Email: c.j.mcdermott@sheffield.ac.uk

Tahir Majeed

Lancashire Teaching Hospital, Preston, UK

Email:Tahir.Majeed@Ithtr.nhs.uk

Ashwin Pinto

Wessex Neurological Centre, Southampton, UK

Email: Ashwin.Pinto@uhs.nhs.uk

Kevin Talbot

University of Oxford, Oxford, UK

Email: kevin.talbot@ndcn.ox.ac.uk

Jannette Walsh

Staffordshire and Stoke on Trent Partnership NHS Trust, Stoke-on-Trent, UK

Email: Jannette.Walsh@ssotp.nhs.uk

Timothy L Williams

Royal Victoria Infirmary, Newcastle upon Tyne, UK

Email:Tim.Williams@nuth.nhs.uk

Alan Tennant

Leeds Institute of Rheumatic and Musculoskeletal Medicine, University of Leeds, UK.

Email: A.Tennant@leeds.ac.uk

TONiC-MND study group*

Corresponding author: Carolyn A. Young, Walton Centre NHS Foundation Trust, Lower Lane, Fazakerley, Liverpool, L9 7LJ, United Kingdom. profcyoung@gmail.com; https://orcid.org/0000-0003-1745-7720

*TONiC-MND study group - Dr CM Ellis, Department of Neurology, Darent Valley Hospital; Dr Hisham Hamdalla, Department of Neurology, Salford Royal Hospital Foundation Trust; Dr Clare Johnston, The York Hospital; Dr Richard W Orrell, UCL Queen Square Institute of Neurology; Dr Rhys C Roberts, Cambridge University Hospitals NHS Foundation Trust. 
Measuring quality of life in ALS/MND: Validation of the WHOQOL-BREF

\begin{abstract}
Objectives: The World Health Organization Quality of Life-BREF Scale (WHOQOLBREF) is a generic QOL measure with four domains covering Physical, Psychological, Social and Environment. Providing the opportunity to contrast QoL with other conditions, or with population norms, the current study had three aims: 1) can the established domains of the WHOQOL-BREF be validated within a large ALS/MND population; 2) can a total score be validated and 3) can they provide interval level measurement?
\end{abstract}

Methods: Data were obtained from the Trajectories of Outcomes in Neurological Conditions study. Internal construct validity was determined by fit of the data to the Rasch measurement model.

Results: 636 participants with ALS/MND were included. All domains, except the Social domain, showed satisfactory fit to the Rasch model. All were unidimensional, and showed no Differential Item Functioning by age, gender, or onset type. Finally, a total score was validated from a bi-factor perspective.

Conclusions: The WHOQOL-BREF is valid for use in populations with ALS/MND and can be analysed to yield interval level measurement: It offers a range of domains that reflect QOL, which can be used for parametric analysis and for comparison with other conditions or general populations, two advantages for its inclusion as a trial outcome measure and for observational studies.

Keywords: Amyotrophic lateral sclerosis, TONiC, quality of life, Rasch, interval level measurement 


\section{Introduction}

Provision of care for people with Motor Neuron Disease (MND), also known as Amyotrophic Lateral Sclerosis (ALS), is enhanced by a thorough understanding of how symptoms and functioning relate to quality of life (QOL). This relationship is expressed in the Wilson and Cleary model, which recognised that symptoms and functioning (health status) are separate to QOL (1). Many widely used HRQOL measures include items covering symptoms and functioning, potentially confounding analysis of how symptoms and functioning affect QOL (2). Furthermore, their weighting toward physical functioning can lead to the interpretation that $\mathrm{QOL}$ declines as the disease progresses (for review, see Simmons 2015) (3). However, studies using measures adopting a broader construct of QOL demonstrate that QOL may be preserved while physical function declines $(4,5)$.

The World Health Organization (WHO) designed broader QOL measures including not only the persons' physical health and psychological state, but also their level of independence, social relationships and their relationship to salient features of their environment (6). The WHO Quality of Life BREF Scale (WHOQOL-BREF) is a shortened version of the 100-item WHOQOL, with 26 items, 24 of which are scored. Its psychometric properties were analysed using data from almost 12,000 adults, with a variety of health states, recruited from hospital, rehabilitation and primary care settings (7). A multi-rater mapping process concluded that the WHOQOL-BREF has the fewest items concerning function out of five widely used generic measures of HRQOL, at $27 \%$ of items in contrast to the $83 \%$ of items concerning function for the Short Form Health Survey (SF-36) or EQ-5D, and even more for the Health Utility Index or SF-12 $(2,8)$.

The aims of the current study were to: a) establish if the original domains of the WHOQOL-BREF can be obtained and validated within a large ALS/MND population; b) to examine if a total score can be validated and c) describe differences in domain scores, using an interval-scaled metric, according to different demographic and clinical characteristics.

\section{Methods}


Data were obtained from an ongoing longitudinal study concerning the trajectories of outcome for those with ALS/MND, the Trajectories of Outcomes in Neurological Conditions (TONiC) study (9). Participants with ALS/MND, diagnosed according to El Escorial World Federation of Neurology criteria (10), were recruited from multidisciplinary specialist clinics across the United Kingdom. Cases with a family history of ALS/MND were eligible as were patients with only lower motor neuron (LMN) signs in 2 or more regions, or with progressive primary lateral sclerosis without spinal LMN signs, provided a consultant neurologist specialising in ALS/MND had confirmed the diagnosis.

Participants were excluded if they were unable to give informed consent, such as from cognitive deficits related to frontotemporal dementia, or if they were unable to complete self-report questionnaires even with help from a scribe. They completed a questionnaire which contained a range of Patient Reported Outcome Measures (PROMs) including the WHOQOL-BREF, Amyotrophic Lateral Rating Scale-Revised (ALSFRS-R), as well as disease duration and site of onset provided by their clinician. All participants received written information and informed consent was obtained prior to enrolment into the study. Ethical approval was granted from the relevant local research committees (reference 11/NW/0743).

\section{Scales}

The WHOQOL-BREF begins with two single summary items on quality of life and health which are not scored with the rest of the item set, and then continues with 24 items covering four domains: (a) Physical health and well-being (seven items); (b) Psychological health and well-being (six items); (c) Social relations (three items); and (d) Environment (eight items). Each item has a five-point rating scale from 0-4 (or sometimes scored 1-5); the higher the item score, the better one's 'quality of life' on the domain covered by the item. While it might be thought that items belonging to the Environment domain would be least likely to represent quality of life, they are worded in such a way that this is exactly the case, for example, "How satisfied are you with the conditions of your living place?" Even for functioning and the classical Activities of Daily Living, rather than the level of difficulty with activities, the question is "How satisfied are you with your ability to perform your daily living activities". Thus while the Physical, Psychological, Social and Environmental domains look, at first sight, to 
be similar to classical 'functioning' scales as found in the Health Related Quality of Life (HRQoL) literature, their perspective is more one of appraisal of aspects related to these domains, rather than the actual 'doing' of tasks related to those domains. It is this that provides a unique perspective upon Quality of Life. Further information including a copy of the WHOQOL-BREF is available from the WHO website at https://www.who.int/mental_health/media/en/76.pdf.

The Amyotrophic Lateral Sclerosis Functional Rating Scale-Revised (ALSFRS-R) was developed to monitor the progression of disability in patients with ALS (11). The 12 items are scored $0-4$ with a total score of 48 , where lower scores indicate greater disability.

Four further scales were included to contribute towards an understanding of the external construct validity of the WHOQOL-BREF:

1. Modified Hospital Anxiety and Depression scale (mHADS), with each domain having six items, and associated clinical cuts to identify 'possible' and 'probable' anxiety or depression (12)

2. World Health Organization's Disability Assessment Schedule-2.0 (WHODAS2.0), which summates 32 items covering communicating, getting around, selfcare, getting along with others, household activities, and participation in society, analysed without the 4 work-related items (13),

3. EQ-5D-5L utility score, measured with a visual analog scale (VAS), which records the respondent's self-rated health status on a graduated (0-100) scale, with higher scores for better HRQOL (14),

4. Numeric Rating Scale (NRS) of perceived overall Quality of Life, where a high score is better.

\section{Statistical analysis}

Internal construct validity of the various domains of the WHOQOL-BREF was determined by fit of the data to the Rasch measurement model, full details of which can be found elsewhere $(15,16)$. Briefly, data must satisfy the requirements of the model, including local item independence, unidimensionality, and stochastic ordering of items (17). Acceptable values of these requirements are shown the foot of the 
fit table. Residual item correlations of 0.2 above the average residual correlations were indicative of local item dependency (18). These dependencies can arise from redundancy, that is, items are close replicates of one another, or from multidimensionality. Where the assumption of local item independence is breached, 'testets' or 'super items' are formed by adding the dependent items together (19). Here we use the term testlet as a group of items which can be identified a priori, for example where there are subscale structures. Where empirical findings show local item dependency without a priori input, we refer to any such subsequent grouping of items as 'super items'. A number of strategies are available for this purpose, depending upon the pattern and extent of local dependency. For example, in the absence of any predefined underlying structure, each pair of locally dependent items can be grouped together into a super item. Also, in the RUMM2030 Rasch software, two testlets/super items absorbing all items can provide a latent estimate based upon a bi-factor equivalent solution where a (stronger) conditional test of fit becomes available (20). The explained common variance (ECV) is reported where a value of 1 indicates that all non-error variance is contained within the latent estimate. An ECV value $>0.9$ is considered sufficient to indicate that the first common (in this case Rasch) factor is essentially unidimensional (21). Values marginally above 1 can be obtained, indicating that some local dependency nevertheless remains across the two testlets/super items. Finally, tests of invariance (Differential Item Functioning (DIF)) of the various domains are made for age, gender and onset type (constrained to limb and bulbar due to small numbers in other groups) (22).

In order to assess external construct validity, Spearman's correlations were analysed between the WHOQOL-BREF total and domains with four other scales: mHADS, WHODAS-2.0, EQ5D-5L utility score and NRS of QOL.

Absolute reliability was determined through the Standard Error of Measurement (SEM) and the Smallest Detectable Difference (SDD). SEM is calculated as SEM = SD all testing scores $\times \sqrt{ }(1-$ reliability). SDD represents the minimal difference that a patient or group must show on the scale to ensure that the observed difference is 
real and not just measurement error, and was calculated as $1.96 \times \sqrt{2} \times$ SEM where 1.96 derives from the $95 \% \mathrm{Cl}(23)$.

\section{Results}

636 patients with ALS/MND returned a baseline questionnaire by early 2018. Mean age was 65.1 years (SD 10.7) and 61.3\% were male (Table 1). Over three quarters (78.6\%) were married, and $40 \%$ considered themselves to be religious or spiritual. Just over three fifths (61\%) were able to complete the questionnaire independently; $85 \%$ completed all the items of the WHOQOL-BREF, and $95 \%$ all but one item. Median ALSFRS-R score was 33.

Initial fit of the data to the Rasch model found that local item dependency was present throughout the scale; within the existing Physical and Psychological domains, and in a total 24-item set. Only the Environmental domain was free of local item dependency; the Social scale had too few items to detect local dependency. For example, in the 24-item set, nine pairs of items showed residual correlations above 0.2 , mostly clustering within established domains. Likewise, independently, the Physical and Psychological domains also showed several pairs of locally dependent items. Consequently, items were grouped to remove the effect of the dependency.

Given this, the fit of the various domains is shown in Table 2. All but the Social domain, showed satisfactory fit to the model. All were unidimensional, and there was no DIF by age, gender, or onset type (bulbar versus limb). Indeed, in the basic 24item analysis (not shown) only the item 'Are you able to accept your bodily appearance' showed DIF by age.

Finally, using the original four domains as testlets, a total score was validated, albeit with $8 \%$ of the variance discarded to obtain the bi-factor unidimensional latent estimate. The person item distribution of the total score is shown in Figure 1. The scale is well targeted, and its range adequately encompasses those of the sample.

Raw score to interval scale transformations for all solutions are shown in Table 3. Providing the respondent has answered all the items within the domain(s) of interest, 
the raw score can be summated by adding the scores of 0-4 for each item. (If the data are scored as $1-5$, then adjust the scores on the transformation table, for example, with the Physical scale of 7 items, add 7 to the raw score and the transformed score). Thus, if interval level measures of Total QOL, or QOL domains concerning Physical, Psychological and Environment are required, the raw score can be converted to an interval scale metric. The metrics have the same operational range as the raw score.

The values of the domains with respect to various demographic, clinical and other PROM-related aspects are shown in Table 4. All domains showed a significant difference and strong gradient across ALSFRS-R levels, with post-hoc analysis showing that all pairwise comparisons were significant with the exception of the comparison between the ALSFRS-R total scores $0-12$ and $13-24$, possibly as a result of the lowest scoring group containing only 8 cases. The Physical domain differed across onset types of limb and bulbar, while most domains did not significantly differ by gender or age.

It is instructive to look at the precision of the domains as expressed through their SEM, their SDD, and the percent of the operational range of the scale implied by the SDD (SDD\%) (Table 5). The WHOQOL-BREF Total score is the most efficient in that just $8.3 \%$ of its operational range needs to be traversed to be above the error. As a contrast, the ALSFRS-R Bulbar domain requires a shift of $33.5 \%$ to be sure that any difference is meaningful and not just influenced by error.

Finally, Table 6 presents the non-parametric (Spearmans) correlations of the WHOQOL-BREF domains (excluding Social) against various other measures included in the study, in order to evaluate external construct validity. As expected, correlations were mostly of moderate strength, with the WHOQOL-BREF Psychological domain showing the strongest correlation with the mHADS Depression scale, and the Physical domain showing a strong correlation with the WHODAS-2.0. It should be noted that the Total score from the WHOQOL-BREF explains $42.2 \%$ of the variance of the NRS QoL Summary item. 


\section{Discussion}

The WHOQOL-BREF has been shown to display internal construct validity for ALS/MND, with the exception of the Social scale which cannot be used as a separate domain, although its items are included in the Total score. Excluding the Social scale, all remaining domains demonstrated invariance of age, gender and onset type and showed acceptable levels of unidimensionality and fit to the Rasch model. Both the Total raw score and the Psychological domain raw score were found to be marginally multidimensional, requiring a bi-factor equivalent solution, and therefore it is necessary to use their respective interval scaled transformed scores, which are based upon a slightly reduced variance. These findings are mostly consistent with those reported by Noerholm et al., who found that in a general population study the physical, psychological and environmental domains fit a twoparameter item response theory model, but not the social domain (24). A bi-factor solution for the Total score of the WHOQOL-BREF has also been proposed elsewhere (25).

Most recently, an ALS/MND-specific QoL scale has been developed with scope for a different QoL end-point where comparability with other conditions or populations is not required (26). In contrast, the WHOQOL-BREF offers a set of domains which is built upon the appraisal of different facets of $\mathrm{QOL}$ and provides a distinctive generic measure of QoL.

There are several strengths emerging from the findings of the study. First, the WHOQOL-BREF is a simple, self-report measure; in this study $85 \%$ of people completed all 26 items at home without any assistance from a researcher. In addition, it appears to have good acceptability among respondents, a further $10 \%$ of people completed 25 out of 26 items. The very low amount of missing data suggests that the items are relevant for people with ALS. This is in keeping with findings in a sample of 4669 people including 27 diagnoses or healthy controls, where just 41 subjects had missing data such that the WHOQOL-BREF could not be scored (27). Secondly, interval scale latent estimates derived from fit of data to the Rasch model provide the required data quality for inclusion in parametric analysis, including path analyses and multi-level modelling. Thirdly, generic scales such as the WHOQOLBREF, offer the advantage of enabling comparisons between conditions and with 
general populations. For example less than $1 \%$ of Australian adults had WHOQOLBREF scores comparable to ALS/MND patients with total ALSFRS-R<13/48 (28). Again, it must be remembered that the WHOQOL-BREF is not about the actual level of functioning, but rather an appraisal of, for example, whether life is thought to be meaningful, whether or not the person is able to accept their bodily appearance, how satisfied they are with their personal relationships, and how safe they feel in their daily life. It is within this perspective that contrasts should be made.

There are further limitations and strengths to the study. The use of the ordinal ALSFRS-R total score has been subjected to some criticism of late, claiming that rather it should be scored as three or four separate domains (29-31). Recently, a possible bi-factor equivalent solution to a total score for the ALSFRS-R has been put forward (32). In the current study the total ordinal score was grouped into quartiles of the operational range of the scale to allow for examination of the gradients of the WHOQOL-BREF domains over these quartiles, based upon a score familiar to most readers. The strengths of the current study include its sample size and wide range of functioning of those with ALS/MND, together with the application of the Rasch measurement model to ascertain internal construct validity.

In summary, the WHOQOL-BREF is valid for use in populations with ALS/MND and, using the transformation table, can be analysed as interval level data across several domains, providing the patient has responded to all the items within the domain(s) of interest. It can provide a Total score, and independent domains of Physical, Psychological and Environmental QOL.

\section{Acknowledgments}

We thank the participants and their families for their invaluable contributions; the research and clinical staff for recruitment, and the TONiC team.

\section{Funding details}

This work was supported by the Motor Neurone Disease Association (UK) under grant Young/Jan15/929-794, and also received research support from the NIHR 
Clinical Research Network, and the Neurological Disability Fund 4530. AAC is supported through the following funding organisations under the aegis of JPND www.jpnd.eu (United Kingdom, Medical Research Council (MR/L501529/1; MR/R024804/1) and Economic and Social Research Council (ES/L008238/1)) and through the Motor Neurone Disease Association. This study represents independent research part-funded by the National Institute for Health Research (NIHR) Biomedical Research Centre at South London and Maudsley NHS Foundation Trust and King's College London. CJM and this research are supported by the NIHR Sheffield Biomedical Research Centre and the NIHR Sheffield Clinical Research Facility. CAY and this research are supported by NIHR CRN NWC.

\section{Disclosure of interest}

The authors report no conflicts of interest.

\section{References}

1. Wilson IB, Cleary PD. Linking clinical variables with health-related quality of life. A conceptual model of patient outcomes. JAMA. 1995;273(1):59-65.

2. Mayo NE, Moriello C, Asano M, van der Spuy S, Finch L. The extent to which common healthrelated quality of life indices capture constructs beyond symptoms and function. Qual Life Res. 2011;20(5):621-7.

3. Simmons Z. Patient-Perceived Outcomes and Quality of Life in ALS. Neurotherapeutics. 2015;12(2):394-402.

4. Robbins RA, Simmons Z, Bremer BA, Walsh SM, Fischer S. Quality of life in ALS is maintained as physical function declines. Neurology. 2001;56(4):442-4.

5. Neudert C, Wasner M, Borasio GD. Individual quality of life is not correlated with healthrelated quality of life or physical function in patients with amyotrophic lateral sclerosis. J Palliat Med. 2004;7(4):551-7.

6. Group TW. The World Health Organization Quality of Life assessment (WHOQOL): position paper from the World Health Organization. Soc Sci Med. 1995;41(10):1403-9.

7. Skevington SM, Lotfy M, O'Connell KA. The World Health Organization's WHOQOL-BREF quality of life assessment: psychometric properties and results of the international field trial. A report from the WHOQOL group. Qual Life Res. 2004;13(2):299-310.

8. The WHOQOL Group. The World Health Organization Quality of Life Assessment (WHOQOL): development and general psychometric properties. Soc Sci Med. 1998;46(12):1569-85.

9. Schlüter DK, Tennant A, Mills R, Diggle PJ, Young CA. Risk factors for social withdrawal in amyotrophic lateral sclerosis/motor neurone disease. Amyotroph Lateral Scler Frontotemporal Degener. 2018;19(7-8):591-8.

10. Brooks BR, Miller RG, Swash M, Munsat TL. El Escorial revisited: revised criteria for the diagnosis of amyotrophic lateral sclerosis. Amyotroph Lateral Scler Other Motor Neuron Disord. 2000;1(5):293-9. 
11. Cedarbaum JM, Stambler N, Malta E, Fuller C, Hilt D, Thurmond B, et al. The ALSFRS-R: a revised ALS functional rating scale that incorporates assessments of respiratory function. BDNF ALS Study Group (Phase III). Journal of the Neurological Sciences. 1999;169(1-2):13-21.

12. Gibbons CJ, Mills RJ, Thornton EW, Ealing J, Mitchell JD, Shaw PJ, et al. Rasch analysis of the hospital anxiety and depression scale (HADS) for use in motor neurone disease. Health Qual Life Outcomes. 2011;9:82-90.

13. Rehm J, Üstün TB, Saxena S, Nelson CB, Chatterji S, Ivis F, et al. On the development and psychometric testing of the WHO screening instrument to assess disablement in the general population. International Journal of Methods in Psychiatric Research. 1999;8(2):110-22.

14. Herdman M GC, Lloyd A, Janssen M, Kind P, Parkin D, Bonsel G, Badia X. Development and preliminary testing of the new five-level version of EQ-5D (EQ-5D-5L). Qual Life Res. 2011 20(10):1727-36.

15. Rasch G. Probabilistic models for some intelligence and attainment tests. Chicago: University of Chicago Press; 1960.

16. da Rocha NS, Chachamovich E, de Almeida Fleck MP, Tennant A. An introduction to Rasch analysis for psychiatric practice and research. Journal of psychiatric research. 2013;47(2):141-8.

17. Gustafsson J. Testing and obtaining fit of data to the Rasch model. British Journal of Mathematical \& Statistical Psychology. 1980;33(2):205-33.

18. Christensen KB, Makransky G, Horton M. Critical Values for Yen's Q3: Identification of Local Dependence in the Rasch Model Using Residual Correlations. Applied psychological measurement. 2017;41(3):178-94.

19. Wainer $\mathrm{H}$, Kiely $\mathrm{G}$. Item clusters and computer adaptive testing: A case for testlets. J Educ Meas. 1987;24(3):185-202.

20. Andrich D. Components of variance of scales with a bifactor subscale structure from two calculations of alpha. Education Measurement: Issue and Practice. 2016;35:25-30.

21. Rodriguez A, Reise S, Haviland M. Evaluating bi-factor models: Calculating and interpreting statistical indices. Psychological Methods. 2016;21:137-50.

22. Teresi JA, Kleinman M, Ocepek-Welikson K. Modern psychometric methods for detection of differential item functioning: application to cognitive assessment measures. Stat Med. 2000;19(1112):1651-83.

23. Stauffer ME, Taylor SD, Watson DJ, Peloso PM, Morrison A. Definition of nonresponse to analgesic treatment of arthritic pain: an analytical literature review of the smallest detectable difference, the minimal detectable change, and the minimal clinically important difference on the pain visual analog scale. International journal of inflammation. 2011;2011:231926.

24. Noerholm V, Groenvold M, Watt T, Bjorner JB, Rasmussen NA, Bech P. Quality of life in the Danish general population--normative data and validity of WHOQOL-BREF using Rasch and item response theory models. Qual Life Res. 2004;13(2):531-40.

25. Perera HN, Izadikhah Z, O'Connor P, Mcllveen P. Resolving Dimensionality Problems With WHOQOL-BREF Item Responses. Assessment. 2018;25(8):1014-25.

26. Felgoise SH, Feinberg R, Stephens HE, Barkhaus P, Boylan K, Caress J, et al. Amyotrophic lateral sclerosis-specific quality of life-short form (ALSSQOL-SF): A brief, reliable, and valid version of the ALSSQOL-R. Muscle Nerve. 2018;58(5):646-54.

27. Skevington SM, McCrate FM. Expecting a good quality of life in health: assessing people with diverse diseases and conditions using the WHOQOL-BREF. Health Expect. 2012;15(1):49-62.

28. de Mol M, Visser S, Aerts J, Lodder P, de Vries J, den Oudsten BL. Satisfactory results of a psychometric analysis and calculation of minimal clinically important differences of the World Health Organization quality of life-BREF questionnaire in an observational cohort study with lung cancer and mesothelioma patients. BMC cancer. 2018;18(1):1173.

29. Franchignoni F, Mora G, Giordano A, Volanti P, Chio A. Evidence of multidimensionality in the ALSFRS-R Scale: a critical appraisal on its measurement properties using Rasch analysis. J Neurol Neurosurg Psychiatry. 2013;84(12):1340-5. 
30. Bacci ED, Staniewska D, Coyne KS, Boyer S, White LA, Zach N, et al. Item response theory analysis of the Amyotrophic Lateral Sclerosis Functional Rating Scale-Revised in the Pooled Resource Open-Access ALS Clinical Trials Database. Amyotroph Lateral Scler Frontotemporal Degener. 2016;17(3-4):157-67.

31. Bakker LA, Schroder CD, van Es MA, Westers P, Visser-Meily JMA, van den Berg LH. Assessment of the factorial validity and reliability of the ALSFRS-R: a revision of its measurement model. J Neurol. 2017;264(7):1413-20.

32. Young C, Paris-Davies J, Mills R, Tennant A, TONiC study group, editors. Can you validly use a total ALSFRS-R score? A Rasch analysis to provide interval scale estimates. 29th International Symposium on ALS/MND; 2018; Glasgow: Amyotrophic Lateral Sclerosis and Frontotemporal Degeneration. 
Figure 1. Person Item Distribution of WHOQOL-BREF Total Score

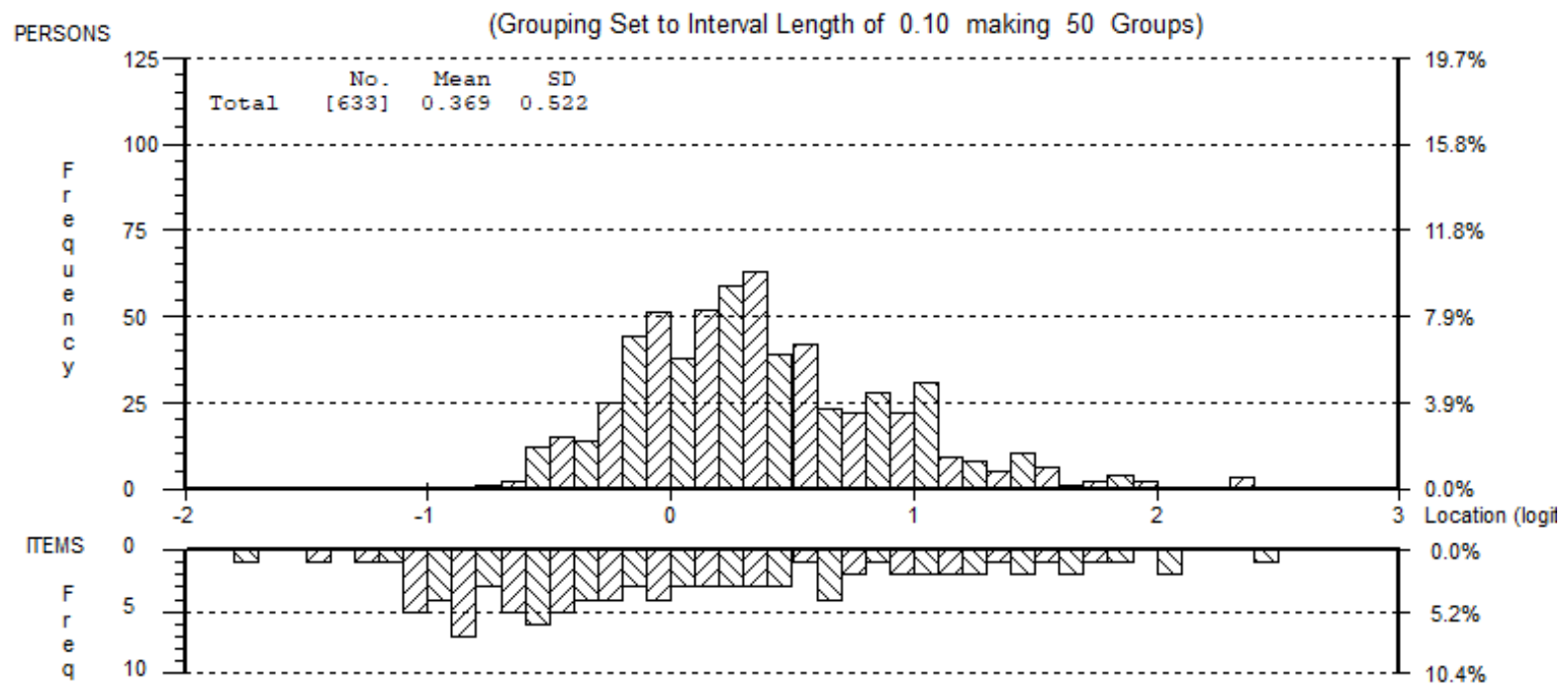


Table 1: Clinical and demographic characteristics of the ALS patients ( $n=636)$.

\begin{tabular}{|l|c|}
\hline Characteristics & ALS patients \\
\hline Gender: Males (\%) & $65.1(10.7)$ \\
\hline Mean age: years (SD) & 78.6 \\
\hline Married (\%): & 40.1 \\
\hline Considered religious or spiritual (\%) & 61.0 \\
\hline Independent completion of Questionnaire (\%) & $428(67.3)$ \\
\hline Site of ALS onset (\%) & $174(27.4 \%)$ \\
\hline Limb & $11(1.7 \%)$ \\
\hline Bulbar & $23(3.6 \%)$ \\
\hline Respiratory & $11.2(4.6-29.9 ; 0.4-295.9)$ \\
\hline Unknown & $33(27-38: 1-48)$ \\
\hline Median disease duration from diagnosis: months (IQR; range) & \\
\hline Median ALS-FRS score (IQR: range) & 22.8 \\
\hline Working activity (\%) & 5.8 \\
\hline Employed & 2.4 \\
\hline Unemployed & 56.1 \\
\hline Retired & \\
\hline Unable to work because of illness or disability & \\
\hline Other & \\
\hline
\end{tabular}

$\mathrm{SD}=$ standard deviation; IQR=Inter Quartile Range; ALSFRS-R=ALS Functional Rating Scale-Revised 
Table 2: Fit of WHOQOL-BREF Domains to Rasch model.

\begin{tabular}{|c|c|c|c|c|c|c|c|c|c|c|c|}
\hline \multirow[t]{2}{*}{ Analysis } & \multirow[t]{2}{*}{ Scale } & \multicolumn{2}{|c|}{ SD of Residuals } & \multicolumn{2}{|c|}{$\begin{array}{l}\text { Chi-Square Fit } \\
\text { statistic }\end{array}$} & \multicolumn{2}{|c|}{ Reliability } & \multirow{2}{*}{$\begin{array}{c}\begin{array}{c}\text { Unidimen- } \\
\text { sionality }\end{array} \\
\text { t-test; } \\
<5 \% \\
\text { (LCI) }\end{array}$} & \multicolumn{3}{|c|}{ Super Item/Testlet Analysis } \\
\hline & & Item & Person & $\begin{array}{l}\text { Value and } \\
\text { (df) }\end{array}$ & $P$ & PSI & Alpha & & $\begin{array}{c}\text { (Average) } \\
\text { Latent } \\
\text { Correlation }\end{array}$ & $\begin{array}{l}\text { Explained } \\
\text { Common } \\
\text { Variance }\end{array}$ & $\begin{array}{c}\text { Conditional Test } \\
\text { of Fit } \\
\text { P value }\end{array}$ \\
\hline 1 & $\begin{array}{c}\text { Physical - } \\
2 \text { super items }\end{array}$ & 0.54 & 0.87 & $\begin{array}{l}11.94 \\
(18)\end{array}$ & 0.850 & 0.82 & 0.82 & 3.7 & 1.00 & 1.00 & 0.030 \\
\hline 2 & $\begin{array}{l}\text { Psychological - } \\
2 \text { super items }\end{array}$ & 0.49 & 098 & $\begin{array}{l}11.79 \\
(18)\end{array}$ & 0.858 & 0.73 & 0.77 & 3.7 & 0.84 & 0.93 & 0.107 \\
\hline 3 & $\begin{array}{l}\text { Social - } \\
3 \text { items }\end{array}$ & 1.46 & 0.83 & $\begin{array}{l}55.34 \\
(20)\end{array}$ & $<0.001$ & 0.57 & 0.57 & 1.9 & - & - & - \\
\hline 4 & $\begin{array}{c}\text { Environmental - } \\
\quad 8 \text { items }\end{array}$ & 1.37 & 1.06 & $\begin{array}{l}100.0 \\
(72)\end{array}$ & 0.016 & 0.77 & 0.78 & $\begin{array}{l}5.6 \\
(3.8)\end{array}$ & - & - & - \\
\hline 5 & $\begin{array}{c}\text { Total score as } 4 \\
\text { domain-based } \\
\text { testlets }\end{array}$ & 2.02 & 1.11 & $\begin{array}{l}19.52 \\
(36)\end{array}$ & 0.988 & 0.85 & 0.81 & 4.3 & 0.827 & 0.921 & - \\
\hline & Ideal Values & $<1.4^{*}$ & $<1.4$ & & $>0.05$ & $>0.7$ & $>0.7$ & $<5.0$ (LCl) & $>0.8$ & $>0.9$ & $>0.01$ \\
\hline
\end{tabular}

*Where testlets/super items are of the same size, else can be inflated; SD= Standard Deviation; PSI=Person Separation Index; $d f=$ Degrees of Freedom ; $\mathrm{LCl}=$ Lower Confidence Interval 
Table 3. Raw score- interval scale metric for total score, and domains.

\begin{tabular}{|c|c|c|c|c|}
\hline $\begin{array}{l}\text { Raw } \\
\text { Score }\end{array}$ & $\begin{array}{c}\text { Overall } \\
\text { Total }\end{array}$ & Physical & Psychological & Environmental \\
\hline 0 & 0.0 & 0.0 & 0.0 & 0.0 \\
\hline 1 & 8.8 & 2.2 & 2.2 & 2.8 \\
\hline 2 & 14.2 & 3.7 & 3.7 & 4.7 \\
\hline 3 & 17.5 & 4.8 & 4.8 & 6.0 \\
\hline 4 & 19.8 & 5.6 & 5.6 & 6.9 \\
\hline 5 & 21.6 & 6.3 & 6.4 & 7.7 \\
\hline 6 & 23.0 & 7.0 & 7.1 & 8.4 \\
\hline 7 & 24.2 & 7.5 & 7.7 & 9.0 \\
\hline 8 & 25.2 & 8.1 & 8.3 & 9.5 \\
\hline 9 & 26.0 & 8.6 & 8.9 & 10.0 \\
\hline 10 & 26.8 & 9.1 & 9.5 & 10.5 \\
\hline 11 & 27.5 & 9.6 & 10.1 & 11.0 \\
\hline 12 & 28.1 & 10.0 & 10.7 & 11.4 \\
\hline 13 & 28.6 & 10.5 & 11.3 & 11.9 \\
\hline 14 & 29.1 & 11.1 & 12.0 & 12.3 \\
\hline 15 & 29.6 & 11.6 & 12.7 & 12.8 \\
\hline 16 & 30.0 & 12.2 & 13.4 & 13.2 \\
\hline 17 & 30.4 & 12.8 & 14.2 & 13.7 \\
\hline 18 & 30.8 & 13.5 & 15.1 & 14.2 \\
\hline 19 & 31.2 & 14.3 & 16.1 & 14.8 \\
\hline 20 & 31.5 & 15.1 & 17.1 & 15.4 \\
\hline 21 & 31.9 & 16.0 & 18.3 & 16.1 \\
\hline 22 & 32.2 & 17.0 & 19.7 & 16.8 \\
\hline 23 & 32.5 & 18.1 & 21.5 & 17.6 \\
\hline 24 & 32.9 & 19.4 & 24.0 & 18.4 \\
\hline 25 & 33.2 & 20.9 & & 19.3 \\
\hline 26 & 33.5 & 22.6 & & 20.4 \\
\hline
\end{tabular}




\begin{tabular}{|c|c|c|c|}
\hline 27 & 33.8 & 24.9 & 21.5 \\
\hline 28 & 34.1 & 28.0 & 22.8 \\
\hline 29 & 34.4 & & 24.3 \\
\hline 30 & 34.8 & & 26.1 \\
\hline 31 & 35.1 & & 28.6 \\
\hline 32 & 35.4 & & 32.0 \\
\hline 33 & 35.7 & & \\
\hline 34 & 36.0 & & \\
\hline 35 & 36.4 & & \\
\hline 36 & 36.7 & & \\
\hline 37 & 37.0 & & \\
\hline 38 & 37.3 & & \\
\hline 39 & 37.7 & & \\
\hline 40 & 38.0 & & \\
\hline 41 & 38.4 & & \\
\hline 42 & 38.7 & & \\
\hline 43 & 39.1 & & \\
\hline 44 & 39.4 & & \\
\hline 45 & 39.8 & & \\
\hline 46 & 40.1 & & \\
\hline 47 & 40.5 & & \\
\hline 48 & 40.9 & & \\
\hline 49 & 41.2 & & \\
\hline 50 & 41.6 & & \\
\hline 51 & 42.0 & & \\
\hline 52 & 42.4 & & \\
\hline 53 & 42.8 & & \\
\hline 54 & 43.2 & & \\
\hline 55 & 43.6 & & \\
\hline 56 & 44.1 & & \\
\hline 57 & 44.5 & & \\
\hline
\end{tabular}




\begin{tabular}{|c|c|}
\hline 58 & 44.9 \\
\hline 59 & 45.4 \\
\hline 60 & 45.9 \\
\hline 61 & 46.4 \\
\hline 62 & 46.8 \\
\hline 63 & 47.4 \\
\hline 64 & 47.9 \\
\hline 65 & 48.4 \\
\hline 66 & 48.9 \\
\hline 67 & 49.5 \\
\hline 68 & 50.1 \\
\hline 69 & 50.7 \\
\hline 70 & 51.3 \\
\hline 71 & 51.9 \\
\hline 72 & 52.5 \\
\hline 73 & 53.2 \\
\hline 74 & 53.8 \\
\hline 75 & 54.5 \\
\hline 76 & 55.2 \\
\hline 77 & 56.0 \\
\hline 78 & 56.7 \\
\hline 79 & 57.5 \\
\hline 80 & 58.3 \\
\hline 81 & 59.1 \\
\hline 82 & 60.0 \\
\hline 83 & 60.9 \\
\hline 84 & 61.8 \\
\hline 85 & 62.8 \\
\hline 86 & 63.9 \\
\hline 87 & 65.1 \\
\hline 88 & 66.4 \\
\hline
\end{tabular}


$89 \quad 67.8$

$90 \quad 69.4$

$91 \quad 71.2$

$92 \quad 73.5$

$93 \quad 76.3$

$94 \quad 80.2$

$95 \quad 86.3$

$96 \quad 96.0$ 
Table 4. Domain Scores (on interval-scaled metric) across various demographic, clincial and other factors. Mean (SD).

$\begin{array}{ccccc}\begin{array}{c}\text { WHOQOL- } \\ \text { BREF } \\ \text { Domains }\end{array} & \text { Physical } & \text { Psychological } & \text { Environmental } & \text { Total } \\ \begin{array}{c}\text { Operational } \\ \text { Range }\end{array} & 0-28 & 0-24 & 0-32 & 0-96 \\ \text { Gender } & & & & \\ \text { Male } & 14.7(3.7) & 13.9^{*} & 19.8 & 48.3 \\ & & (3.1) & (4.0) & (7.3) \\ \text { Female } & 14.4(3.9) & 13.2^{*} & 19.8 & 47.7 \\ & & (3.4) & (4.3) & (7.7) \\ \text { Age } & & & & \\ \text { Up to } 66 & 14.5(3.9) & 13.6 & 19.5 & 47.8 \\ & & (3.3) & (4.3) & (7.6) \\ 67 \text { and } & 14.7(3.6) & 13.6 & 20.1 & 48.4 \\ \text { above } & & (3.2) & (4.0) & (7.2)\end{array}$

\section{Onset Type}

$\begin{array}{ccccc}\text { Bulbar } & 14.5^{*} & 13.7 & 20.9^{*} & 49.6^{*} \\ & (4.3) & (3.5) & (4.4) & (8.4) \\ \text { Limb } & 14.2^{*} & 13.6 & 19.3^{*} & 47.5^{*} \\ & (3.4) & (3.2) & (3.9) & (6.9) \\ \text { Respiratory } & 14.3 & 13.9 & 21.5 & 48.8 \\ & (3.2) & (3.3) & (4.3) & (7.3) \\ \text { Unknown } & 14.6(4.8) & 13.5 & 20.2 & 48.6 \\ & & (3.6) & (3.9) & (8.2)\end{array}$

$\begin{array}{ccccc}\begin{array}{c}\text { ALSFRS-R } \\ \text { Total** }\end{array} & & & & \\ 48-37 & 17.0 & 14.9 & 21.5 & 52.2 \\ & (3.7) & (3.1) & (4.4) & (7.6) \\ 36-25 & 14.1 & 13.5 & 19.4 & 47.3 \\ & (3.1) & (3.0) & (3.8) & (6.5) \\ 24-13 & 11.6 & 11.6 & 17.9 & 42.9 \\ & (2.4) & (3.0) & (3.4) & (4.6) \\ 12-0 & 10.1 & 10.1 & 16.9 & 39.9 \\ & (2.6) & (2.6) & (3.6) & (3.2)\end{array}$

* Indicates satistical difference at 0.05 (posthoc tests where apropriate)

${ }^{* *}$ All pairwise comparisons significant except that between the lowest two groups 
Table 5. Precision of the WHOQOL-BREF domains and, for comparison, ALSFRS-R domains. All domains are on an interval scaled metric.

\section{Domain}

WHOQOL-

\section{BREF}

Physical

Psychological

Environmental

Total

\section{Mean}

SD

SEM

SDC

$\%$ SDC

\section{ALSFRS-R}

Bulbar

8.218

33.478

Limb

Respiratory
13.073

10.341
3.325

1.449

4.017

3.775

3.265

4.137

7.408

5.266

2.106

5.839

0.838

1.922
2.020

1.531

1.940

2.869

5.615

4.245

5.379

7.953

20.055

17.687

16.808

8.284

$\mathrm{SD}=$ Standard Deviation; SEM = Standard Error of Measurement; SDD = Smallest Detectable Difference; \%SDD is that difference as \% of operational range of the scale. 
Table 6. WHOQOL-BREF domains correlated with other relevant scales.

\begin{tabular}{|c|c|c|c|c|c|}
\hline & $\begin{array}{c}\text { WHODAS- } \\
32\end{array}$ & EQ-5D-5L & $\begin{array}{c}\text { mHADS } \\
\text { Anxiety }\end{array}$ & $\begin{array}{c}\text { mHADS } \\
\text { Depression }\end{array}$ & NRS-QoL \\
\hline $\begin{array}{c}\text { WHOQOL- } \\
\text { BREF }\end{array}$ & -0.6706 & 0.7283 & -0.3555 & -0.5328 & 0.5567 \\
\hline Physical & -0.4914 & 0.4791 & -0.6119 & -0.7329 & 0.6015 \\
\hline Psychological & -0.5107 & 0.5139 & -0.3725 & -0.4935 & 0.5408 \\
\hline Environmental & -0.6489 & 0.6651 & -0.5000 & -0.6787 & 0.6493 \\
\hline Total & & & & & \\
\hline
\end{tabular}

